\title{
Incidence and Characteristics of Endophthalmitis after Cataract Surgery in Poland, during 2010-2015
}

\author{
Michał S. Nowak ${ }^{1,2, *} \mathbb{0}$, Andrzej Grzybowski ${ }^{3,4} \mathbb{D}$, Katarzyna Michalska-Małecka ${ }^{5}$, \\ Jacek P. Szaflik ${ }^{6}$, Milena Kozioł ${ }^{7}$, Wojciech Niemczyk ${ }^{7}$ and Iwona Grabska-Liberek ${ }^{8}$ (i) \\ 1 Provisus Eye Clinic, Czestochowa 42-209, Poland \\ 2 Saint Family Hospital Medical Center, Lodz 90-302, Poland \\ 3 Department of Ophthalmology, University of Warmia and Mazury, Olsztyn 10-082, Poland; \\ ae.grzybowski@gmail.com \\ 4 Institute for Research in Ophthalmology, Foundation for Ophthalmology Development, Poznan 60-554, \\ Poland \\ 5 Department of Ophthalmology, School of Medicine in Katowice, Medical University of Silesia, \\ Katowice 40-952, Poland; k.michalska.malecka@gmail.com \\ 6 Department of Ophthalmology, SPKSO (Samodzielny Publiczny Kliniczny Szpital Okulistyczny) \\ Ophthalmic Hospital, Medical University of Warsaw, Warsaw 03-709, Poland; jacek@szaflik.pl \\ 7 Department of Analyses and Strategies, Polish Ministry of Health, Warsaw 00-952, Poland; \\ m.koziol@mz.gov.pl (M.K.); w.niemczyk@mz.gov.pl (W.N.) \\ 8 Department of Ophthalmology, Centre of Postgraduate Medical Education, 231 Czerniakowska str., \\ Warsaw 01-416, Poland; iliberek@gmail.com \\ * Correspondence: michaelnovak@interia.pl; Tel.: +48-888-801-010
}

Received: 12 May 2019; Accepted: 17 June 2019; Published: 20 June 2019

\begin{abstract}
Background: The assessment of the incidence and characteristic of acute and chronic postoperative endophthalmitis (POE) after cataract surgery in Poland during 2010-2015. Patients and methods: All hospitalizations of patients, in the National Database of Hospitalizations, who underwent cataract surgery alone or in combined procedures in Poland between January 2010 and December 2015, with a billing code of endophthalmitis, were selected. Acute endophthalmitis was identified if symptoms occurred within 1-42 days from the cataract surgery and chronic endophthalmitis if symptoms occurred $\geq 43$ days after cataract surgery, respectively. Results: In total, 1331 cases of POE after 1,218,777 cataract extractions were identified. The overall incidence of POE decreased from $0.125 \%$ in 2010 to $0.066 \%$ in 2015 . In multiple logistic regression analyses, increasing age was significantly associated with acute POE, while type II diabetes mellitus, extracapsular cataract extraction, and one-day surgery were significantly associated with chronic POE. The combined cataract surgery and male sex were significant risk factors for both acute and chronic POE. A total of $62.51 \%$ of all eyes affected by POE received antibiotic treatment and $37.49 \%$ had vitrectomy treatment. Conclusions: During the study period, the total incidence of postoperative endophthalmitis after cataract surgery decreased significantly.
\end{abstract}

Keywords: cataract surgery; acute endophthalmitis; chronic endophthalmitis

\section{Introduction}

Postoperative endophthalmitis is a serious complication of cataract surgery, with the incidence varying from $0.02 \%$ to $0.71 \%$ according to recent studies. These studies also revealed a significant decline in the incidence of postoperative endophthalmitis in the twenty-first century [1,2]. The results of the European Association of Cataract and Refractive Surgeons (ESCRS) report showed that the use of intracameral cefuroxime at the end of the cataract surgery significantly reduced the occurrence of 
postoperative endophthalmitis as well as improved the surgery techniques with the use of injectable lenses, topical anesthesia, and microincisions [3]. According to this report, the existing risk factors for postoperative endophthalmitis included clear corneal incisions, the use of silicone intraocular lenses, and the presence of surgical complications [3]. Although the ESCRS endophthalmitis report was based on a multicenter, international study and comprised 16,603 participants, its results were published over a decade ago [3].

Globally, cataract surgery is the most common ocular surgery; however, reports on the incidence of endophthalmitis after cataract on a national level are limited [4,5]. In 2013, Friling et al. [6] reported the incidence of endophthalmitis in the Swedish National Cataract Register from 2005 to 2010. In 2016, Creuzot-Garcher et al. [7] reported the incidence of acute postoperative endophthalmitis in France from 2005 to 2014. Two studies from Canada [8,9] published data from the State Control for Health Insurance Plan regarding all cataract surgeries performed during 1996-2005 in Quebec province and during 2002-2006 in Ontario province. The aim of the present study was to assess the incidence and characteristic of endophthalmitis after cataract surgery in the overall population of Poland from 2010 to 2015. Our study was part of a project titled "Maps of Healthcare Needs-Database of Systemic and Implementation Analyses," which was co-financed by the European Union funds through the European Social Fund under the Operational Program Knowledge, Education, and Development [10].

\section{Materials and Methods}

In Poland, the National Health Fund (Narodowy Fundusz Zdrowia-NFZ) maintains the national database of hospitalizations, which records all medical procedures in public and private hospitals financed from public sources. The national database of hospitalizations provides accurate population-based medical data, which include the diagnoses coded according to the International Classification of Diseases, 10th Revision (ICD-10), and all procedures performed, coded using the International Classification of Diseases, 9th Revision (ICD-9), procedure codes and unique NFZ codes corresponding to certain hospital procedures. It also compiles the socio-demographic data of all patients including personal identification number (PESEL), age, sex, and place of residence. Our study design was a population-based retrospective epidemiological survey. The subject sampling method was published in our previous studies. In brief: "The data from the national database of hospitalizations from all patients who underwent cataract surgery alone or in combined procedures in Poland between January 2010 and December 2015 were assessed [11]. For each individual patient, cataract surgery alone or as a combined procedure with corneal transplantation, glaucoma filtration surgery, or vitrectomy was retrospectively identified. The ICD-9 code 13.4 was used to identify cataract extraction performed by phacoemulsification, with 13.2, 13.3, and 13.5 codes used to identify other types of cataract extractions. The following NFZ codes were used: B12-B15, B18, and B19 with regard to cataract surgery alone; B04-B06 with regard to cataract surgery combined with corneal transplantations; B11 with regard to cataract surgery followed by glaucoma filtration surgery; B16 and B17 with regard to cataract surgery combined with vitrectomy." The ICD-10 codes H44.0 and H44.1 were used to identify endophthalmitis. All hospitalizations of patients who underwent cataract surgery alone or in combined procedures in Poland during the researched period, with a billing code of endophthalmitis, were selected. Acute endophthalmitis was diagnosed if the symptoms occurred within 1-42 days after cataract surgery and chronic endophthalmitis was diagnosed if the symptoms occurred $\geq 43$ days after cataract surgery. Patients with diabetes mellitus (DM) were identified with ICD-10, E10, and E11 codes and received DM medication before cataract surgery. Population data were obtained from the Central Statistical Office of Poland (Głowny Urzad Statystyczny-GUS) [12].

The statistical analysis included the annual volume of cataract surgery, calculations of incidence of both acute and chronic endophthalmitis, and the demographic and surgical characteristics of patients with endophthalmitis (the socio-demographic data including age, sex, and place of residence were anonymously recorded). Independent Wald tests were used for risk factor analysis. Multiple logistic regression statistics were used to investigate the association of endophthalmitis with several risk 
factors, including age, gender, rural residence, one-day procedure, combined surgery, extracapsular cataract extraction surgical technique, surgery in a non-multidisciplinary hospital and the presence of diabetes mellitus. Odds ratios (ORs) were computed. $p$-values less than 0.05 were considered statistically significant. The study protocol adhered to the tenets of the Declaration of Helsinki for research involving human subjects and was approved by the Polish Ministry of Health. The Polish Ministry of Health is entitled to process the National Health Fund's data by the law of Republic of Poland, so we do not have any ethical approval number.

\section{Results}

Cataract surgery and postoperative endophthalmitis: Table 1 shows the total number of postoperative endophthalmitis (POE) cases and the total number of all cataract surgeries performed in Poland alone or as combined procedures with vitrectomy, glaucoma filtration surgery, and corneal transplantation, between January 2010 and December 2015, matched with population data by age group. In the researched period, the number of cataract surgeries in Poland increased by $17.9 \%$ from 201,083 cases in 2010 to 237,098 cases in 2015, with a significant decrease in the years 2011-2013. In total, 1,218,777 cataract extractions (alone or combined with other procedures) were performed during 2010-2015.

Table 1. The total number of postoperative endophthalmitis (POE) cases and the total number of cataract surgeries performed in Poland from 2010-2015 matched with population data by age group.

\begin{tabular}{|c|c|c|c|c|c|c|}
\hline & 2010 & 2011 & 2012 & 2013 & 2014 & 2015 \\
\hline No. of $0-18$ year-olds & $7,643,553$ & $7,630,880$ & $7,531,582$ & $7,431,731$ & $7,367,066$ & $7,309,001$ \\
\hline No. of cataract surgeries & 245 & 267 & 272 & 294 & 270 & 242 \\
\hline No. with endophthalmitis & 0 & 0 & 0 & 0 & 0 & 0 \\
\hline No. of 19-39 year-olds & $12,482,309$ & $12,523,386$ & $12,461,398$ & $12,355,235$ & $12,201,430$ & $12,015,345$ \\
\hline No. of cataract surgeries & 1441 & 1305 & 1280 & 1324 & 1383 & 1384 \\
\hline No. with endophthalmitis & 5 & 5 & 3 & 10 & 8 & 4 \\
\hline No. of $40-49$ year-olds & $4,792,211$ & $4,822,159$ & $4,838,436$ & $4,879,816$ & $4,956,005$ & $5,064,587$ \\
\hline No. of cataract surgeries & 3007 & 2680 & 2620 & 2583 & 2849 & 2920 \\
\hline No. with endophthalmitis & 7 & 9 & 4 & 6 & 6 & 4 \\
\hline No. of 50-59 year-olds & $5,770,823$ & $5,765,460$ & $5,656,651$ & $5,536,118$ & $5,406,320$ & $5,245,352$ \\
\hline No. of cataract surgeries & 15,598 & 13,397 & 13,203 & 13,188 & 14,645 & 14,001 \\
\hline No. with endophthalmitis & 11 & 27 & 20 & 22 & 19 & 18 \\
\hline No. of 60-69 year-olds & $3,682,048$ & $3,931,289$ & $4,171,206$ & $4,409,809$ & $4,642,821$ & $4,888,294$ \\
\hline No. of cataract surgeries & 38,973 & 35,322 & 37,986 & 43,120 & 52,747 & 57,646 \\
\hline No. with endophthalmitis & 46 & 43 & 49 & 59 & 53 & 42 \\
\hline No. with age $\geq 70$ years & $4,146,056$ & $3,852,826$ & $3,874,727$ & $3,889,291$ & $3,910,358$ & $3,932,421$ \\
\hline $\begin{array}{c}\text { No. of cataract } \\
\text { surgeries }\end{array}$ & 141,819 & 122,035 & 126,644 & 134,212 & 156,970 & 160,905 \\
\hline No. with endophthalmitis & 183 & 160 & 145 & 154 & 120 & 89 \\
\hline Total No. & $38,517,000$ & $38,526,000$ & $38,534,000$ & $38,502,000$ & $38,484,000$ & $38,455,000$ \\
\hline No of cataract surgeries & 201,083 & 175,006 & 182,005 & 194,721 & 228,864 & 237,098 \\
\hline No. with endophthalmitis & 252 & 244 & 221 & 251 & 206 & 157 \\
\hline
\end{tabular}

Among these cataract surgeries, 1331 were associated with postoperative endophthalmitis (POE), including 584 cases of acute POE (within 42 days from cataract surgery) and 747 chronic POE ( $\geq 42$ days after cataract surgery) (Table 2). The overall incidence of POE decreased from $0.125 \%$ in 2010 to $0.066 \%$ in 2015 (with the mean incidence of $0.109 \%$ ). The incidences of acute and chronic POE decreased from $0.047 \%$ and $0.078 \%$ in 2010 to $0.035 \%$ and $0.031 \%$ in 2015 , respectively (Table 2 ). The differences between the incidences of acute, chronic, and the total number of POE during 2010-2015 were statistically 
significant $(p=0.0018, p=0.0147$, and $p=0.0000$, respectively) with a temporal increase in the incidence of POE during 2011-2013.

Table 2. Incidence of acute and chronic postoperative endophthalmitis (POE) after cataract surgery in Poland from 2010-2015.

\begin{tabular}{cccccccc}
\hline Year & $\begin{array}{c}\text { No. of } \\
\text { Cataract } \\
\text { Surgeries }\end{array}$ & $\begin{array}{c}\text { No. of } \\
\text { Cases of } \\
\text { Acute } \\
\text { POE }\end{array}$ & $\begin{array}{c}\text { Incidence } \\
\text { of Acute } \\
\text { POE (\%) }\end{array}$ & $\begin{array}{c}\text { No. of } \\
\text { Cases of } \\
\text { Chronic } \\
\text { POE }\end{array}$ & $\begin{array}{c}\text { Incidence } \\
\text { of Chronic } \\
\text { POE (\%) }\end{array}$ & $\begin{array}{c}\text { Total } \\
\text { Number } \\
\text { of Cases } \\
\text { of POE }\end{array}$ & $\begin{array}{c}\text { Total } \\
\text { Incidence } \\
\text { of POE } \\
\text { (\%) }\end{array}$ \\
\hline 2010 & 201,083 & 95 & 0.047 & 157 & 0.078 & 252 & 0.125 \\
\hline 2011 & 175,006 & 95 & 0.054 & 149 & 0.085 & 244 & 0.139 \\
\hline 2012 & 182,005 & 97 & 0.053 & 124 & 0.068 & 221 & 0.121 \\
\hline 2013 & 194,721 & 118 & 0.061 & 133 & 0.068 & 251 & 0.129 \\
\hline 2014 & 228,864 & 96 & 0.042 & 110 & 0.048 & 206 & 0.09 \\
\hline 2015 & 237,098 & 83 & 0.035 & 74 & 0.031 & 157 & 0.066 \\
\hline Total & $1,218,777$ & 584 & 0.048 & 747 & 0.061 & 1331 & 0.109 \\
\hline
\end{tabular}

The demographic and surgical characteristics of all cases of POE are presented in Tables 3 and 4. The mean age of subjects with acute POE was $71.2 \pm 11.9$ years and for those with chronic POE was $73.7 \pm 12.1$ years. In Poland, $28.85 \%$ of all cases of POE were identified in rural residents and $42.30 \%$ in men. Diabetes mellitus type I and type II were diagnosed in $4.43 \%$ and $18.78 \%$ of subjects with postoperative endophthalmitis, respectively. The extracapsular cataract extraction surgical technique was used in $5.94 \%$ of cases and $32.61 \%$ were identified after one-day cataract surgery. Postoperative endophthalmitis occurred in 137 eyes $(10.30 \%)$ after cataract surgery combined with pars plana vitrectomy, in 20 eyes $(1.50 \%)$ after cataract surgery combined with glaucoma filtration surgery, and in 16 eyes $(1.20 \%)$ after cataract surgery combined with corneal transplantation. Young males had relatively more POE probably due to traumatic cataract. A total of $62.51 \%$ of all eyes affected by POE in Poland during 2010-2015 received antibiotic treatment and 37.49\% had vitrectomy treatment (with a rate of $44.86 \%$ among the cases of acute POE) (Figure 1).

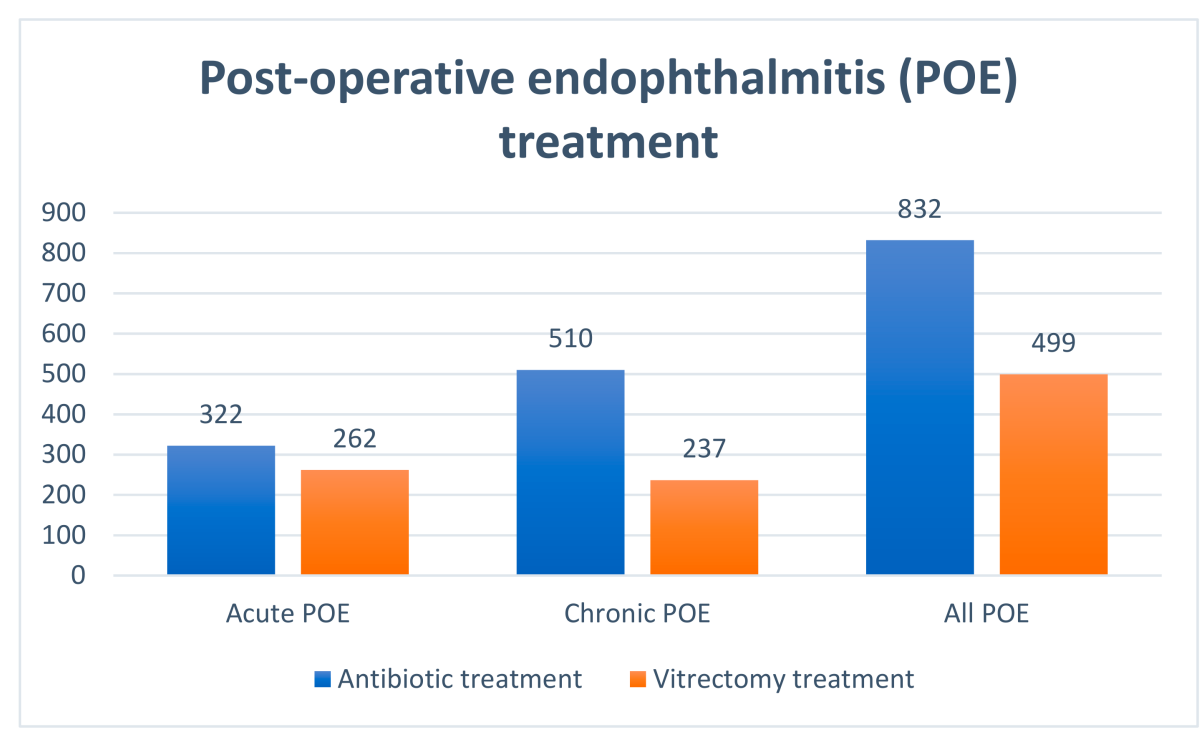

Figure 1. Treatment of postoperative endophthalmitis (POE) after cataract surgery in Poland during 2010-2015. 
Table 3. Demographic characteristics of all postoperative endophthalmitis (POE) cases after cataract surgery in Poland during 2010-2015.

\begin{tabular}{cccc}
\hline & $\begin{array}{c}\text { Acute POE } \\
\boldsymbol{n}(\boldsymbol{\%}) ; \text { Rate Per 1000 } \\
\text { Surgeries }\end{array}$ & $\begin{array}{c}\text { Chronic POE } \\
\boldsymbol{( \% )} ; \text { Rate Per 1000 } \\
\text { Surgeries }\end{array}$ & $\begin{array}{c}\text { Total Number of POE } \\
\boldsymbol{n} \text { (\%); Rate Per 1000 } \\
\text { Surgeries }\end{array}$ \\
\hline Age: & $0(0.00 \%) ; 0.000$ & $0(0.00 \%) ; 0.000$ & $0(0.00 \%) ; 0.000$ \\
\hline $0-18$ & $22(3.77 \%) ; 2.710$ & $13(1.74 \%) ; 1.601$ & $35(2.63 \%) ; 4.311$ \\
\hline $19-39$ & $16(2.74 \%) ; 0.960$ & $20(2.68 \%) ; 1.200$ & $36(2.70 \%) ; 2.160$ \\
\hline $40-49$ & $51(8.73 \%) ; 0.607$ & $66(8.83 \%) ; 0.785$ & $117(8.79 \%) ; 1.392$ \\
\hline $50-59$ & $125(21.40 \%) ; 0.470$ & $167(22.36 \%) ; 0.628$ & $292(21.94 \%) ; 1.098$ \\
\hline $60-69$ & $370(63.36 \%) ; 0.439$ & $481(64.39 \%) ; 0.570$ & $851(63.94 \%) ; 1.009$ \\
\hline $70+$ & & & \\
\hline Sex & $328(56.16 \%) ; 0.413$ & $440(58.90 \%) ; 0.554$ & $768(57.70 \%) ; 0.967$ \\
\hline Women & $256(43.84 \%) ; 0.602$ & $307(41.10 \%) ; 0.773$ & $563(42.30 \%) ; 1.325$ \\
\hline Men & $408(69.86 \%) ; 0.454$ & $539(72.15 \%) ; 0.600$ & $947(71.15 \%) ; 1.054$ \\
\hline Urban residence & $176(30.14 \%) ; 0.568$ & $208(27.85 \%) ; 0.671$ & $384(28.85 \%) ; 1.239$ \\
\hline Rural residence & $24(4.11 \%) ; 0.248$ & $35(4.69 \%) ; 0.361$ & $59(4.43 \%) ; 0.609$ \\
\hline Diabetes mellitus t. I & $99(16.95 \%) ; 0.399$ & $151(20.21 \%) ; 0.609$ & $250(18.78 \%) ; 1.008$ \\
\hline Diabetes mellitus t. II & $461(78.94 \%) ; 0.527$ & $561(75.10 \%) ; 0.642$ & $1022(76.79 \%) ; 1.169$ \\
\hline No diabetes mellitus & & &
\end{tabular}

Table 4. Surgical characteristics of all postoperative endophthalmitis (POE) cases after cataract surgery in Poland during 2010-2015.

\begin{tabular}{lccc}
\hline & Acute POE $\boldsymbol{n}$ (\%) & Chronic POE $\boldsymbol{n}$ (\%) & Total Number of POE $\boldsymbol{n}$ (\%) \\
\hline $\begin{array}{l}\text { Cataract surgery in multidisciplinary } \\
\text { hospital }\end{array}$ & $559(95.72 \%)$ & $704(94.24 \%)$ & $1263(94.89 \%)$ \\
\hline $\begin{array}{l}\text { Cataract surgery in } \\
\text { non-multidisciplinary hospital }\end{array}$ & $25(4.28 \%)$ & $43(6.76 \%)$ & $68(5.11 \%)$ \\
\hline $\begin{array}{l}\text { Surgical technique } \\
\text { phacoemulsification }\end{array}$ & $561(96.06 \%)$ & $691(92.50 \%)$ & $1252(94.06 \%)$ \\
\hline $\begin{array}{l}\text { Surgical technique extracapsular } \\
\text { extraction }\end{array}$ & $23(3.94 \%)$ & $56(7.50 \%)$ & $79(5.94 \%)$ \\
\hline One-day cataract surgery & $219(37.50 \%)$ & $215(28.78 \%)$ & $434(32.61 \%)$ \\
\hline Non one-day cataract surgery & $365(62.50 \%)$ & $532(71.22 \%)$ & $897(67.39 \%)$ \\
\hline $\begin{array}{l}\text { Cataract surgery combined with } \\
\text { corneal transplantation }\end{array}$ & $0(0.00 \%)$ & $16(2.14 \%)$ & $16(1.20 \%)$ \\
\hline $\begin{array}{l}\text { Cataract surgery combined with } \\
\text { glaucoma filtration surgery }\end{array}$ & $4(0.68 \%)$ & $16(2.14 \%)$ & $20(1.50 \%)$ \\
\hline $\begin{array}{l}\text { Cataract surgery combined with pars } \\
\text { plana vitrectomy }\end{array}$ & $71(12.16 \%)$ & $66(8.84 \%)$ & $137(10.30 \%)$ \\
\hline \begin{tabular}{l} 
Non-combined cataract surgery \\
\hline
\end{tabular} & $509(87.16 \%)$ & $649(86.88 \%)$ & $1158(87.00 \%)$ \\
\hline
\end{tabular}

\section{Multiple Logistic Regression Modeling}

Multivariate logistic regression models were constructed to analyze the risk factors for acute and chronic postoperative endophthalmitis (POE) after cataract surgery in Poland during 2010-2015 (Table 5). The sensitivity/specificity evaluation of multiple logistic regression models for acute and chronic postoperative endophthalmitis with receiver operating characteristic (ROC) curves are presented in Figures 2 and 3. Our analysis showed that acute POE was significantly associated with age (OR 0.99, 95\% confidence interval (CI) 0.98-1.00) and male sex (OR 1.35, 95\% CI 1.11-1.64). Chronic POE was also significantly associated with male sex (OR 1.28, 95\% CI 1.08-1.53) as well as with type 
II diabetes mellitus (OR 1.42, 95\% CI 1.18-1.75), extracapsular cataract extraction (OR 3.09, 95\% CI $2.20-4.23$ ), and one-day surgery (OR $0.75,95 \% \mathrm{CI} 0.61-0.91)$. The combined cataract surgery was a significant risk factor for both acute and chronic POE (OR 4.25, 95\% CI 3.09-5.74 and OR 4.41, 95\% CI $3.38-5.67$, respectively). No association was found between acute and chronic POE with surgery in a non-multidisciplinary hospital or with rural residence of our study subjects.

Table 5. Multiple logistic regression models of the risk factors for acute and chronic postoperative endophthalmitis (POE).

\begin{tabular}{ccc}
\hline Variables & $\begin{array}{c}\text { Acute POE } \\
\text { OR, 95\% CI, } p \text {-value }\end{array}$ & $\begin{array}{c}\text { Chronic POE } \\
\text { OR, 95\% CI, } p \text {-value }\end{array}$ \\
\hline Age, per year increase & $0.99(0.98-1.00) ; p=0.047$ & $1.00(0.99-1.01) ; p=0.454$ \\
\hline Men vs. women & $1.35(1.11-1.64) ; p=0.003$ & $1.28(1.08-1.53) ; p=0.005$ \\
\hline Rural residence & $1.22(0.98-1.50) ; p=0.069$ & $0.98(0.80-1.18) ; p=0.811$ \\
\hline Type II diabetes mellitus & $1.18(0.91-1.52) ; p=0.198$ & $1.42(1.18-1.75) ; p=0.001$ \\
\hline Extracapsular extraction & $1.40(0.77-2.31) ; p=0.226$ & $3.09(2.20-4.23) ; p=0.000$ \\
\hline One-day surgery & $1.11(0.90-1.36) ; p=0.323$ & $0.75(0.61-0.91) ; p=0.004$ \\
\hline Combined cataract surgery & $4.25(3.09-5.74) ; p=0.000$ & $4.41(3.38-5.67) ; p=0.000$ \\
\hline Surgery in a non-multidisciplinary hospital & $0.77(0.47-1.17) ; p=0.246$ & $0.87(0.58-1.24) ; p=0.474$ \\
\hline
\end{tabular}

$\mathrm{OR}=$ odds ratio; $\mathrm{CI}=$ confidence interval.

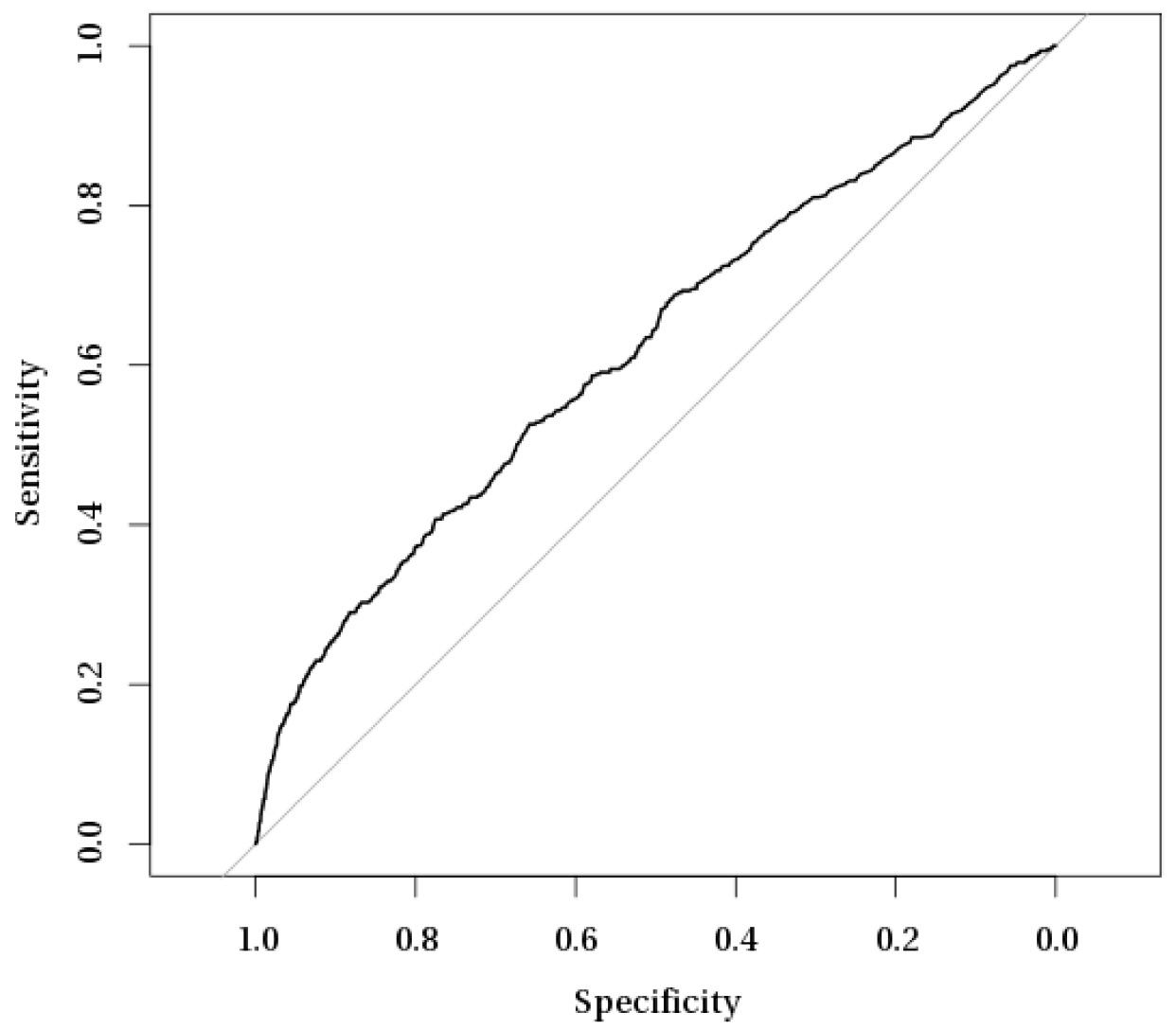

Area under the curve $(\mathrm{AUC})=0.63$.

Figure 2. Receiver operating characteristic (ROC) curve analysis of sensitivity/specificity evaluation of multiple logistic regression model for acute postoperative endophthalmitis. 


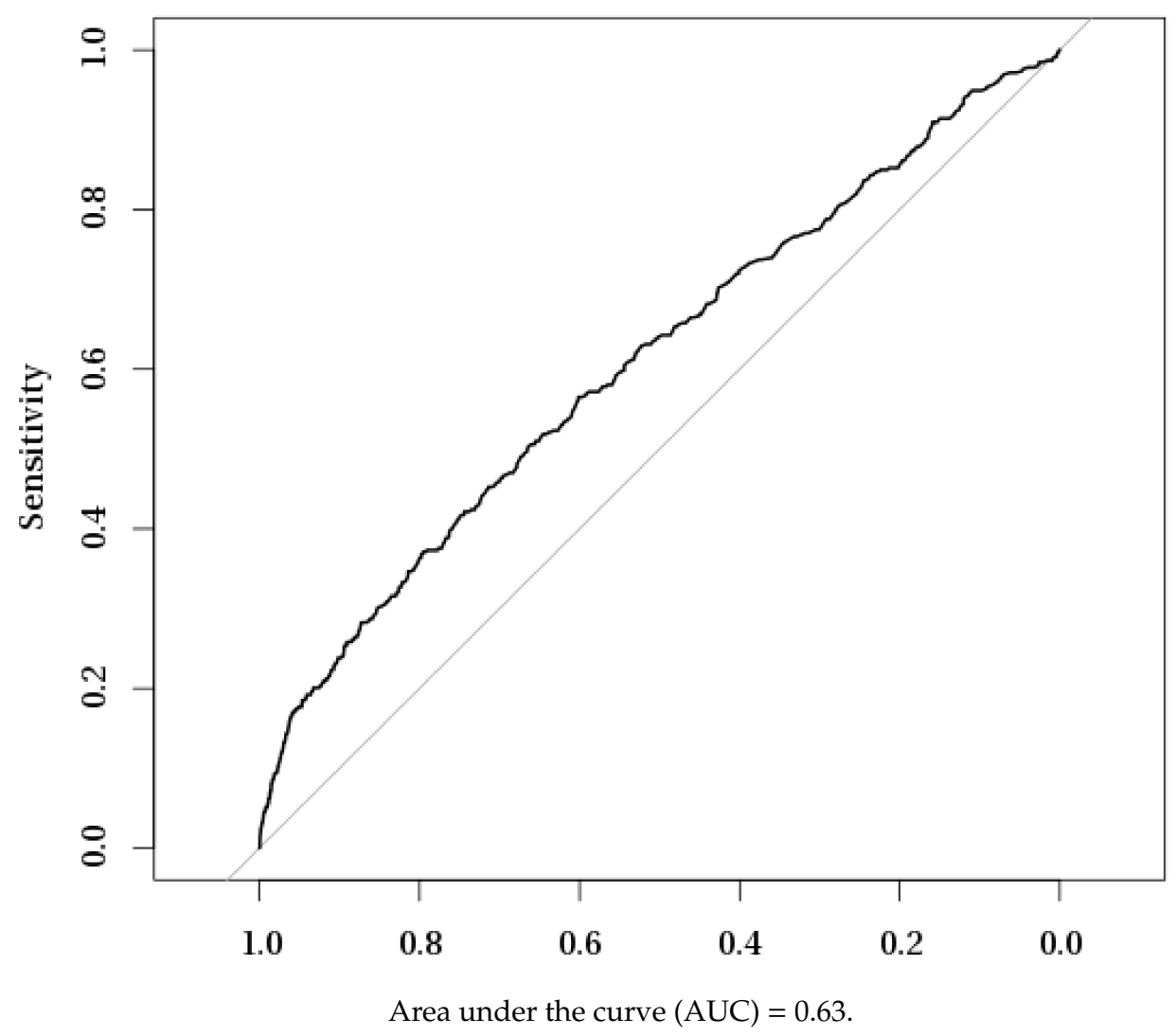

Figure 3. Receiver operating characteristic (ROC) curve analysis of sensitivity/specificity evaluation of multiple logistic regression model for chronic postoperative endophthalmitis.

\section{Discussion}

Our study provides, for the first time, data concerning the incidence and characteristics of postoperative endophthalmitis (POE) after cataract surgery in Eastern Europe. The study evaluates the trends of acute and chronic POE after cataract surgery in the overall population of Poland in the years 2010-2015. During the study period, the total number of all POE cases decreased from 252 in the 2010 to 157 in the 2015, while the total number of cataract surgeries increased from 201,083 cases in the 2010 to 237,098 cases in 2015. The overall incidence of POE decreased from $0.125 \%$ in 2010 to $0.066 \%$ in 2015 , with a significant decrease in the incidences of both acute and chronic POE.

Our findings are in agreement with the results of recent studies from other countries, which showed a significant decrease in the incidence of POE after cataract surgery over time $[6,7,13-15]$. The results of the recent studies of POE which comprised over 100,000 participants are presented in Table 6 . Our total incidence rate of POE $(0.109 \%)$ was similar to the rate found in a nationwide study in France [7]. It was lower than the rates found in Canada and the Medicare Database in USA $[8,9,13]$ and was higher than the rates found in Malaysia, Sweden, and in members of Kaiser Permanente, California, USA $[6,14,16]$. But these studies recorded only the incidence of acute postoperative endophthalmitis after cataract surgery. Our total incidence rate of acute POE was rather low $(0.048 \%)$ and was the second lowest among nationwide studies after the incidence rate in Sweden. In Poland, the recorded incidence rate of chronic POE in the years 2010-2015 (0.061\%) was higher than that of acute POE. However, during the study period it was reversed and, in the year 2015, the incidence of acute POE was higher than the incidence of chronic POE. Direct comparison of our results to the results obtained in studies from Iran and India [2,17] is limited due to the difference in study design. Although they comprised over 100,000 participants, those two studies were single-hospital studies. Between the years 2010 and 2015, no simultaneous bilateral endophthalmitis was officially reported in Poland, since the legal regulations for immediate sequential bilateral cataract surgery (ISBCS) were introduced in 
January 2017. However, the results of recently published studies on ISBCS revealed that when the guidelines for strict separation of the two surgical procedures were followed, as well as after separate bilateral cataract surgeries less than five days apart, no simultaneous bilateral endophthalmitis was detected $[18,19]$. We analyzed the surgical characteristic of cataract surgery in Poland to find the possible explanation for the acute and chronic POE decrease over the years. We found that during the study period the total number of one-day cataract surgeries significantly increased, while the use of extracapsular lens extraction significantly decreased [10].

Table 6. Comparison of the incidence rates of postoperative endophthalmitis (POE) from recent studies which comprised over 100,000 participants.

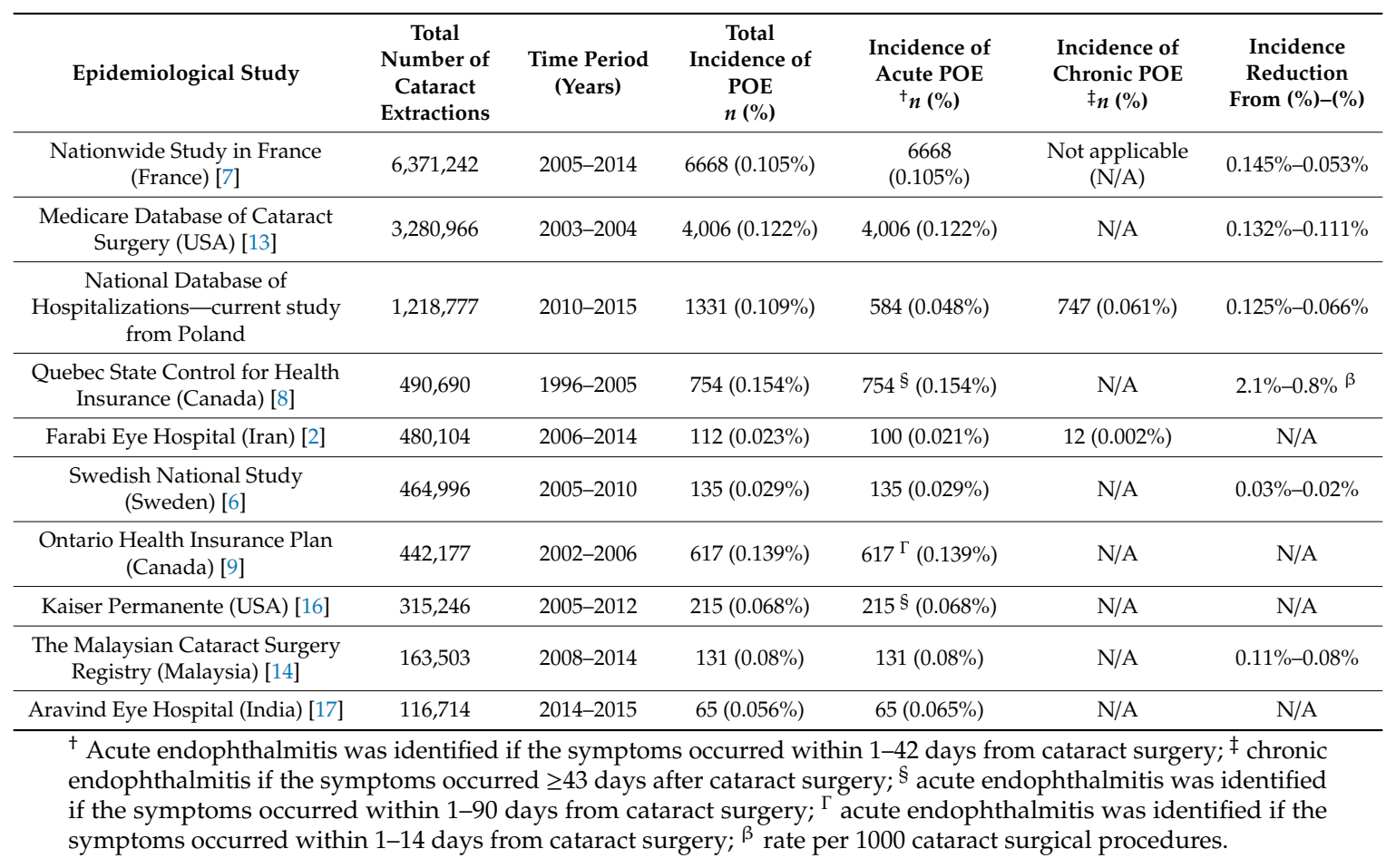

In our study, increasing age was significantly associated with acute POE, while type II diabetes mellitus, extracapsular cataract extraction, and one-day surgery were significantly associated with chronic POE. The combined cataract surgery and male sex were significant risk factors for both acute and chronic POE. Our findings were in agreement with the results of some previous studies, which revealed that acute POE was significantly associated with older age, male gender, black race, diabetes mellitus, presence of renal disease as well as extracapsular cataract extraction, cataract surgery combined with other procedures, intraoperative posterior capsule rupture, and non-use of intracameral antibiotic $[2,6,7,13,14,16,20,21]$.

Although intracameral cefuroxime (Aprokam, Laboratoires Thea, Clermont-Ferrand, France) was commercially available in Poland since 2012, we did not include the intracameral antibiotic injection into the multiple regression analysis of endophthalmitis risk factors. This procedure was not widely used during the study period due to the significant reduction in the reimbursement cost of cataract surgery by the National Health Fund. This cost reduction was also a possible factor of the temporary increase in the incidence of POE in the years 2011-2013.

There are some limitations related to the present study. The major limitation is the possible presence of misclassification. The diagnosis of endophthalmitis was based on clinical presentation rather than a stricter bacteriological definition. Other limitations include errors in using specific ICD-10, ICD-9, and NFZ codes. However, such mistakes likely had only a minor impact on the study findings, because the present study was country based and covered the overall population of Poland. During 
the study period, the use of an intracameral antibiotic injection at the end of the cataract surgery was not officially reported in the NFZ national database of hospitalizations as well as other possible risk factors such as surgical complications and the type of intraocular lens (IOL) used. However, the cost-effectiveness of the use of intracameral antibiotics in reduction of the substantial costs associated with the treatment of POE after cataract surgery is well known [22].

\section{Conclusions}

In summary, our study showed, for the first time, the incidence of acute and chronic POE after cataract surgery in the overall population of Poland in the years 2010-2015 as well as the existing risk factors. During the study period, the total incidence of postoperative endophthalmitis after cataract surgery decreased significantly, while the total the number of cataract surgeries significantly increased. Globally, large population-based data regarding the incidence rate of chronic POE are still lacking. The present study is the first nationwide study which reports the prevalence of chronic POE after cataract surgery.

Author Contributions: Conceptualization and methodology, M.S.N. and A.G.; Data curation, M.K. and W.N.; Investigation and formal analysis, M.S.N., A.G., I.G.-L., K.M.-M., and J.P.S.; Writing- original draft, M.S.N.; Validation, A.G. and I.G.-L.; Writing- review and editing, M.S.N.

Funding: This paper has been prepared within the project Maps of Health Needs-Database of Systemic and Implementation Analyses. The project is co-financed by the European Union from the European Social Fund under the Operational Program Knowledge, Education, and Development, and it is being carried out by the Analyses and Strategies Department of the Polish Ministry of Health.

Acknowledgments: We would like to thank Barbara Więckowska Ph.D. for administrative support during the study period.

Conflicts of Interest: The authors declare no conflict of interest.

\section{References}

1. Chen, Y.H.; Chen, J.T.; Tai, M.C.; Chou, Y.C.; Chen, C.L. Acute postcataract endophthalmitis at a referral center in northern Taiwan: Causative organisms, clinical features, and visual acuity outcomes after treatment: A retrospective cohort study. Medicine 2017, 96, e8941. [CrossRef] [PubMed]

2. Jabbarvand, M.; Hashemian, H.; Khodaparast, M.; Jouhari, M.; Tabatabaei, A.; Rezaei, S. Endophthalmitis Occurring after Cataract Surgery: Outcomes of More Than 480,000 Cataract Surgeries, Epidemiologic Features, and Risk Factors. Ophthalmology 2016, 123, 295-301. [CrossRef] [PubMed]

3. Endophthalmitis Study Group, European Society of Cataract \& Refractive Surgeons. Prophylaxis of postoperative endophthalmitis following cataract surgery: Results of the ESCRS multicenter study and identification of risk factors. J. Cataract Refract. Surg. 2007, 33, 978-988. [CrossRef] [PubMed]

4. Packer, M.; Chang, D.F.; Dewey, S.H.; Little, B.C.; Mamalis, N.; Oetting, T.A.; Talley-Rostov, A.; Yoo, S.H. Prevention, diagnosis, and management of acute postoperative bacterial endophthalmitis. J. Cataract Refract. Surg. 2011, 37, 1699-1714. [CrossRef] [PubMed]

5. Kessel, L.; Flesner, P.; Andresen, J.; Erngaard, D.; Tendal, B.; Hjortdal, J. Antibiotic prevention of postcataract endophthalmitis: A systematic review and meta-analysis. Acta Ophthalmol. 2015, 93, 303-317. [CrossRef] [PubMed]

6. Friling, E.; Lundström, M.; Stenevi, U.; Montan, P. Six-year incidence of endophthalmitis after cataract surgery: Swedish national study. J. Cataract Refract. Surg. 2013, 39, 15-21. [CrossRef] [PubMed]

7. Creuzot-Garcher, C.; Benzenine, E.; Mariet, A.S.; de Lazzer, A.; Chiquet, C.; Bron, A.M.; Quantin, C. Incidence of Acute Postoperative Endophthalmitis after Cataract Surgery: A Nationwide Study in France from 2005 to 2014. Ophthalmology 2016, 123, 1414-1420. [CrossRef] [PubMed]

8. Freeman, E.E.; Roy-Gagnon, M.-H.; Fortin, É; Gauthier, D.; Popescu, M.; Boisjoly, H. Rate of Endophthalmitis After Cataract Surgery in Quebec, Canada, 1996-2005. Arch. Ophthalmol. 2010, 128, 230. [CrossRef] [PubMed]

9. Hatch, W.V.; Cernat, G.; Wong, D.; Devenyi, R.; Bell, C.M. Risk Factors for Acute Endophthalmitis after Cataract Surgery: A Population-based Study. Ophthalmology 2009, 116, 425-430. [CrossRef] [PubMed] 
10. Nowak, M.S.; Grabska-Liberek, I.; Michalska-Małecka, K.; Grzybowski, A.; Kozioł, M.; Niemczyk, W.; Wieckowska, B.; Szaflik, J.P. Incidence and Characteristics of Cataract Surgery in Poland, during 2010-2015. Int. J. Environ. Res. Public Heal. 2018, 15, 435. [CrossRef] [PubMed]

11. The National Registry Data. 2018. Available online: http://www.nfz.gov.pl (accessed on 21 August 2018).

12. Statistical Office of Poland Data. Available online: http://www.stat.gov.pl (accessed on 21 August 2018).

13. Keay, L.; Gower, E.W.; Cassard, S.D.; Tielsch, J.M.; Schein, O.D. Postcataract surgery endophthalmitis in the United States: Analysis of the complete 2003 to 2004 Medicare database of cataract surgeries. Ophthalmology 2012, 119, 914-922. [CrossRef] [PubMed]

14. Wai, Y.Z.; Chew, L.M.F.; Mohamad, A.S.; Ang, C.L.; Chong, Y.Y.; Adnan, T.H.; Goh, P.-P.; Chew, F.L.M.; Salowi, M.A. The Malaysian cataract surgery registry: Incidence and risk factors of postoperative infectious endophthalmitis over a 7-year period. Int. J. Ophthalmol. 2018, 11, 1685-1690. [PubMed]

15. Oh, B.-L.; Lee, J.S.; Lee, H.Y.; Yu, H.G. Change in Nationwide Incidence of Post-Cataract Surgery Endophthalmitis: Korean Cohort Study from 2002 to 2013. Ocul. Immunol. Inflamm. 2018, 28, 1-6. [CrossRef] [PubMed]

16. Herrinton, L.J.; Shorstein, N.H.; Paschal, J.F.; Liu, L.; Contreras, R.; Winthrop, K.L.; Chang, W.J.; Melles, R.B.; Fong, D.S. Comparative Effectiveness of Antibiotic Prophylaxis in Cataract Surgery. Ophthalmology 2016, 123, 287-294. [CrossRef] [PubMed]

17. Haripriya, A.; Chang, D.F.; Namburar, S.; Smita, A.; Ravindran, R.D. Efficacy of Intracameral Moxifloxacin Endophthalmitis Prophylaxis at Aravind Eye Hospital. Ophthalmology 2016, 123, 302-308. [CrossRef] [PubMed]

18. Arshinoff, S.A.; Bastianelli, P.A. Incidence of postoperative endophthalmitis after immediate sequential bilateral cataract surgery. J. Cataract Refract. Surg. 2011, 37, 2105-2114. [CrossRef] [PubMed]

19. Chen, Y.; Zhang, Y.; Li, X.; Yan, H. Incidence of acute-onset endophthalmitis after separate bilateral cataract surgeries less than 5 days apart. BMC Ophthalmol. 2019, 25, 32. [CrossRef] [PubMed]

20. Gower, E.W.; Keay, L.J.; Stare, D.E.; Arora, P.; Cassard, S.D.; Behrens, A.; Tielsch, J.M.; Schein, O.D. Characteristics of Endophthalmitis after Cataract Surgery in the United States Medicare Population. Ophthalmology 2015, 122, 1625-1632. [CrossRef] [PubMed]

21. Creuzot-Garcher, C.P.; Mariet, A.S.; Benzenine, E.; Daien, V.; Korobelnik, J.F.; Bron, A.M.; Quantin, C. Is combined cataract surgery associated with acute postoperative endophthalmitis? A nationwide study from 2005 to 2014. Br. J. Ophthalmol. 2018, 136, 1352-1358. [CrossRef] [PubMed]

22. Schmier, J.K.; Hulme-Lowe, C.K.; Covert, D.W.; Lau, E.C. An updated estimate of costs of endophthalmitis following cataract surgery among Medicare patients: 2010-2014. Clin. Ophthalmol. 2016, 26, 2121-2127. [CrossRef] [PubMed]

(C) 2019 by the authors. Licensee MDPI, Basel, Switzerland. This article is an open access article distributed under the terms and conditions of the Creative Commons Attribution (CC BY) license (http://creativecommons.org/licenses/by/4.0/). 